\title{
PARADIGMAS DO ENSINO JURÍDICO E SUAS INFLUÊNCIAS NA FORMAÇÃO DO PROFISSIONAL DO DIREITO
}

\section{PARADIGMS OF LEGAL EDUCATION AND ITS INFLUENCES IN THE TRAINING OF THE PROFESSIONAL OF THE LAW}

\author{
Nazaré Portilho Amaral Castro ${ }^{1}$, Cláudia Regina de Oliveira Cantanhede ${ }^{2}$
}

RESUMO: Este artigo tem como objetivo analisar os paradigmas que norteiam o ensino jurídico no Brasil e as tendências necessárias à formação discente para o século XXI. Urge nos espaços em sala de aula o desenvolvimento e compromisso efetivo com práticas que superem a dimensão compartimentalizada, dogmática e procedimentalista do fazer o Direito. Foi realizado um estudo da literatura e da legislação federal que apontam a necessidade de formação profissional com ênfase na postura crítica e reflexiva para com a Ciência do Direito. Sugere-se a mediação dos saberes das temáticas jurídicas em sala de aula, utilizando-se as metodologias ativas do ensino. É necessária construção de processos de ensino calcados na busca constante do conhecimento e numa postura reflexiva que almeja a formação fundada nas habilidades e competências delineadas pelas Diretrizes Curriculares Nacionais.

PALAVRAS-CHAVE: Paradigmas. Ensino Jurídico. Legislação. Possibilidades Metodológicas.

ABSTRACT: This paper aims to analyze the paradigms that guide the legal education in Brazil and the trends necessary for students training for the twenty-first century. It urges the spaces in the classroom, the development and effective commitment to practices that exceed the compartmentalized size, dogmatic and proceduralist of making Law. A study of literature and federal legislation that indicates the need for vocational training with an emphasis on critical and reflective attitude towards Science of Law was carried out. It is suggested the mediation of legal thematic knowledge in the classroom using active teaching methodologies. It needs the construction of footwear teaching processes in constant pursuit of knowledge and a reflective stance that aims at training based on the skills and competencies outlined by the National Curriculum Guidelines.

KEY WORDS: Paradigms. Legal Education. Legislation. Methodological Possibilities.

\footnotetext{
${ }^{1}$ Graduada em Pedagogia. Graduada em Direito (Egressa do Curso de Direito da Universidade CEUMA). Mestra em Ensino em Ciências da Saúde. Pós-graduação em Nutrição e Saúde aplicada à Prática Pedagógica. Pedagoga do Núcleo de Apoio ao Docente e Discente (NADD) da Universidade CEUMA. E-mail: nazareportilho@ yahoo.com.br ${ }^{2}$ Graduada em Ciências Sociais e em Direito. Mestra em Educação. Professora na Universidade CEUMA.

E-mail: c.r.back@bol.com.br
} 


\section{INTRODUÇÃO}

Atualmente, a sociedade está vivenciando um momento em que a Globalização, o Capitalismo, as estruturas sociais e políticas que subjazem no país provocam reflexões sobre os diversos paradigmas que envolvem o contexto contemporâneo social. Dentre esses paradigmas, direcionamos nossos olhares para os que permeiam o ensino jurídico nos curso de graduação em Direito, com a intenção de fazer uma análise sobre suas influências no ensino e, consequentemente, na formação profissional.

No cenário atual, os paradigmas educacionais que norteiam os cursos de Direito no Brasil, muitas vezes, entram em choque com a dimensão holística das habilidades e competências esperadas dos egressos desses cursos, propostas pelas Diretrizes Curriculares Nacionais.

$\mathrm{Na}$ análise feita no campo teórico-conceitual, não houve a pretensão de trazer diagnósticos e soluções simplistas, mas realizar uma leitura mais detida e realista do âmbito no qual se vê inserida a educação jurídica. Há a preocupação, de forma específica, em clarificar a concepção de produção de conhecimento adotada pelo método tradicional de ensino jurídico e a perspectiva dialético-crítica no ensino jurídico.

O modelo de ensino delineado nas instituições universitárias traduzem modelos do campo das Ciências. É aqui que adentramos o paradigma dogmático ou positivista do Direito, o qual fincou bases sólidas no Direito. É uma concepção clássica, que tem seus postulados na Ciência moderna e limiar do século XX, com sua preocupação restrita com a norma legal, descolada da realidade histórica e social. Essa tendência inibe a capacidade crítica do indivíduo, tida como um importante mecanismo de construção pessoal que favorece a participação comprometida com os anseios da sociedade.

Não obstante, vivemos em um momento histórico extremamente acelerado pelos meios de produção, altamente influenciada pelas novas tecnologias, meios de comunicação que favorecem continuamente redes diferenciadas na busca de conhecimento e que põem em evidência a necessidade de superação, conforme o modelo positivista para o paradigma da dialética social do Direito, que se firma enquanto paradigma emancipatório; de crítica às estruturas conservadoras e tradicionais que sedimentam as sociedades excludentes e elitistas, as quais fazem do Direito um instrumento para legitimação dessas estruturas.

Ademais, na transição do século XX para XXI houve um crescimento acelerado dos cursos de Direito no país. E aqui se insere a preocupação com o ensino jurídico, tendo em vista as 
mudanças que se fazem necessárias para o empreendimento de novos parâmetros de formação, dos quais não comportam mais a formação de um profissional passivo. Dessa análise, esperam-se subsídios para se pensar em outras abordagens didático-metodológicas que propiciem estudos alternativos para formação jurídica.

Para a realização deste trabalho, a pesquisa bibliográfica e a documental foram utilizadas. Na pesquisa bibliográfica foi percorrida a literatura com base em autores como Amaral (2014), Berbel (2011), Martinez (2003), Wolkmer (2015a, 2015b), Santos (2002), os quais, dentre outros, definem as bases teórico-metodológicas que priorizam as discussões no âmbito do ensino jurídico e os traços que o caracterizam, a fim de possibilitar uma leitura das concepções paradigmáticas existentes. Na pesquisa documental foi analisada a Constituição Federal Brasileira (1988), a Lei de Diretrizes e Bases da Educação Nacional- LDB, as Diretrizes Curriculares Nacionais - DCN's, com propostas e direcionamento, que, paralelamente, reforçam o desenvolvimento de um processo educativo favorável às discussões e reflexões críticas que visam à formação jurídica mais ampla.

Por fim, a título de conclusão, apresentam-se os resultados e discussões obtidos com o exame minucioso da literatura e documentos para tecer as reflexões.

\section{O PARADIGMA DOGMÁTICO OU POSITIVISTA}

Essa concepção político-ideológica do fenômeno jurídico edificou-se sob a égide do racionalismo cartesiano, no qual o positivismo jurídico representava os valores político-econômicos do liberalismo burguês laissez-faire, laissez-passer no plano do Direito (WOLKMER, 2015a). Concepção que considera o Direito aquilo que se encontra formalmente disposto no ordenamento legal, sendo desnecessário qualquer juízo de valor acerca de seu conteúdo.

Segundo Wolkmer (2015a), o paradigma positivista imperou no século XIX, incidindo seus reflexos em diversos países, entre eles o Brasil, deixando cravadas suas características na forma de conduzir o processo de ensino.

A centralidade curricular do paradigma positivista reside na reprodução do corpus do saber jurídico como supremacia dos demais saberes, bastando ao aluno cumprir sua tarefa de reproduzir literalmente o saber ensinado pelo professor em sala de aula. Basta saber a lei e aplicá-la no contexto dado. Na linha de entendimento desse paradigma, é desnecessário saber o contexto de 
produção da norma jurídica, restringindo a atuação do operador jurídico em conhecer a lei e saber aplicá-la na sua profissão.

Aos poucos esse paradigma, tendo em vista o quadro de mudanças sociais, políticas, econômicas e educacionais, foi perdendo espaço, abrindo o debate em torno de um novo paradigma científico para as Ciências como um todo e, também, para as Ciências sociais, que, de uma maneira mais específica, vêm sendo realizadas ao longo dos anos. A crise dessa percepção remete à crise dos tempos modernos, na qual a evolução científica, em que nos encontramos, não corresponde mais às premissas do racionalismo cartesiano (SANTOS, 2002).

Verifica-se que o saber científico encontra-se amarrado às crendices das concepções cientificistas e positivistas. Essa estrutura fixa e estável é incapaz de responder às demandas e às novas necessidades educativas de um mundo atual em profundas transformações.

Na visão de Branco (2014), os problemas atuais são problemas sistêmicos que expressam a visão mecanicista, reducionista e fragmentária que aflige, indistintamente, a produção do conhecimento no ensino jurídico e, consequentemente, não atende a essa complexidade contemporânea.

Cumpre observar que as reflexões sobre a crise paradigmática formal ensejaram o surgimento de várias teorias críticas que, através dos seus discursos, procuram desconstruir o paradigma da Ciência Jurídica Positivista, criando outras bases epistemológicas para a compreensão do fenômeno jurídico. Esta desconstrução vem ocorrendo à medida em que as reflexões críticas promovem revisões paradigmáticas das matrizes teórico-metodológicas a serem utilizadas (MIKOS \& VILLATORE, 2016).

Wolkmer (2015b) apresenta o modelo crítico-interdisciplinar da racionalidade emancipatória como forma epistemológica de suplementação do modelo tradicional de racionalidade da educação tecnoformal.

São imprescindíveis, no ensino jurídico, estudos interdisciplinares que envolvam a interface com a Pedagogia, a Filosofia, a Psicologia, a Sociologia, a História, as quais são áreas de conhecimento que servirão para trazer lucidez e a compreensão dos fenômenos que envolvem as práticas de um país em desenvolvimento (RODRIGUES \& ARRUDA, 2012).

Nesse passo de estudos interdisciplinares, há mais possibilidades de reflexão a respeito dos direitos humanos, da solidariedade e da responsabilidade cidadã e com o país, vislumbrando uma formação em que as injustiças sociais poderão ser minimizadas e a sociedade caminhará em rumos de novas perspectivas (FEFERBAUM\&GHIRARDI, 2012). 
Em meio ao caos de instabilidade e euforia social, político e econômico que se instalou no país, essa possibilidade somente poderá acontecer com as premissas práticas de mecanismos de ações concretas democráticas e de respeito à liberdade, à dignidade e à igualdade de todos. $\mathrm{O}$ Direito abriga a Justiça, a anticorrupção e o respeito às normas necessárias impostas por ele como justas, levando-se em conta as características e direitos fundamentais de todos os seres humanos, conforme preconiza a Constituição Federal (BRASIL, 1988).

Embora o país tenha delineado sua história no ensino jurídico construindo sobre a matriz de ideais liberais, baseado na adoção de currículos privatistas e metodologias pedagógicas tradicionais, tem havido um movimento de educadores comprometidos nos cursos de Direito na realização da tarefa de reconstrução e atualização das universidades para atender com eficácia às novas demandas da atualidade (MARTINEZ, 2003).

Nesse contexto, convém relembrar a tríade que confere sustentação ao ensino superior: o Ensino, a Pesquisa e a Extensão. Em contraposição ao que se observa em muitas instituições de ensino superior, entende-se a pesquisa como elemento integrante do ensino. A pesquisa, além de fazer parte da formação do professor, é também imprescindível para o desenvolvimento e formação do aluno.

A Lei n 9394/96 - Lei de Diretrizes e Bases da Educação Nacional (LDB) aborda, como uma das finalidades da educação superior, o desenvolvimento de atividades de pesquisa e iniciação científica, in verbis:

Art. 43 - A educação superior tem por finalidade:

III - incentivar o trabalho de pesquisa e investigação científica, visando o desenvolvimento da ciência e da tecnologia e da criação e difusão da cultura, e, desse modo, desenvolver o entendimento do homem e do meio em que vive; [...] (BRASIL, 1996).

Tendo em vista o que diz a legislação, a Educação Superior, de forma geral (em Instituições de Ensino Superior credenciadas ou não como Universidades), tem por finalidade incentivar o trabalho de pesquisa e de investigação científica. Ou seja, a obrigatoriedade da pesquisa não se restringe às universidades.

Quando há integração entre Ensino e Pesquisa nas atividades do professor e dos alunos, há uma melhoria do ensino e, consequentemente, da formação do profissional, permitindo formar sujeitos autônomos, participativos e críticos, capacitados a refletir e produzir novos conhecimentos acerca de sua prática profissional.

A Resolução do Conselho Nacional de Educação/Câmara de Educação SuperiorCNE/CES n. ${ }^{\circ}$ 9/2004, que trata das Diretrizes Curriculares Nacionais (DCN), em seu artigo $2^{\circ}, \S 1^{\circ}$, 
inciso VII, estabelece que o Projeto Pedagógico do Curso, além da clara concepção do curso de Direito, enseja seu currículo pleno e sua operacionalização, os quais abrangerão, sem prejuízo de outros, o incentivo à Pesquisa e à Extensão, como necessário prolongamento da atividade de ensino e como instrumento para a iniciação científica (BRASIL, 2004).

Ademais, no art. $3^{\circ}$ das DCN's encontram-se os dispositivos relativos ao perfil que se espera de seus egressos e às habilidades e competências que devem desenvolver ao longo do curso:

Art. $3^{\circ}$. O curso de graduação em Direito deverá assegurar, no perfil do graduando, sólida formação geral, humanística e axiológica, capacidade de análise, domínio de conceitos e da terminologia jurídica, adequada argumentação, interpretação e valorização dos fenômenos jurídicos e sociais, aliada a uma postura reflexiva e de visão crítica que fomente a capacidade e a aptidão para a aprendizagem autônoma e dinâmica, indispensável ao exercício da ciência do Direito, da prestação da justiça e do desenvolvimento da cidadania. (BRASIL, 2004)

Portanto, concorda-se com Santos (2002), quando destaca o estudo do campo da Hermenêutica e da Interpretação, da Retórica, da Linguagem e da Argumentação como forma de atenuar as lacunas da crise epistemológica do conhecimento e buscar desvelar as estruturas conservadoras que prejudicam o ensino jurídico.

Com fulcro nesses posicionamentos, inicia-se a discussão acerca dos processos de desenvolvimento de uma educação jurista que contemple uma dialética considerando-se os antagonismos sociais.

\section{O PARAdIGMA DIALÉTICO OU TEORIA CRÍTICA NO ENSINO DO DIREITO}

Esse movimento dialético não é novo: ele emergiu desde a Antiguidade Clássica. Destarte, mesmo sendo empreendido além dos tempos, ainda vem consolidando-se e buscando espaços na universidade frente às mudanças e com as constantes alterações na sociedade e na legislação.

Em face dessa realidade extremamente inconstante e emergente, que muda frente às constantes alterações sócio-políticas e econômicas, cumpre considerar que se vivencia, na atualidade, segundo Wolkmer (2015b), uma das fases mais dicotômicas do Capitalismo avançado com as dificuldades econômicas, a grande concentração de corporações internacionais, a formação de blocos econômicos e integração de mercado, bem como o desnivelamento das riquezas do país, estas concentradas cada vez mais nas mãos de poucos. 
Assim sendo, essa realidade aparente implica ser necessário revisitar um novo modo de conceber, entender e praticar o Direito. Essas exigências recaem sobre a Ciência Jurídica em seu aspecto epistemológico, pois ocorrem transformações no seu objeto, alterações na maneira de interpretá-lo, analisá-lo e de estabelecer conexões.

Com a evolução das relações sócio-jurídicas, sobretudo no ponto de vista do Direito Público, com ênfase na relação Estado-indivíduo, a democratização dos processos decisórios, com vistas à consolidação da cidadania e democracia efetivamente participativas na crise estrutural, torna-se momento propício para a aplicabilidade de novas concepções e paradigmas do Direito (MIKOS, 2016).

Frisa-se que, embora ainda se encontrem arraigados no meio acadêmico os métodos de inspiração positivistas e mesmo sendo um instrumento de aplicabilidade incisiva do Direito, suas amarras e limitações não dão mais conta da extraordinária demanda de produção do conhecimento jurídico (COELHO, 2003).

Ademais, para Coelho (2003), essa visão entra em contramão com as vias de desenvolvimento social, político e de novos saberes jurídicos que se emanam constantemente. Há uma luta interna, que ganha cada vez mais espaço para impedir o retorno ao Estado de arbitrariedade estatal típico do absolutismo, o qual não mais se presta à interpretação e aplicação judiciais do Direito em face das novas e sucessivas ordens constitucionais e legais que embasam os Estados modernos.

A evolução constante das relações jurídicas, concebidas em sua complexidade, exige uma teoria crítica consistente no modo de encarar o Direito como prática social específica, na qual estão expressos historicamente os conflitos, os acordos e as tensões dos grupos sociais que atuam em uma formação social determinada (COELHO, 2003).

Depreende-se que o conhecimento jurídico é parte do conhecimento da formação social em sua totalidade e de suas transformações na história, tendo o labor hermenêutico, como não sendo uma tarefa puramente técnica ou analítica, mas sobretudo política, alimentada pelas contribuições da hermenêutica jurídica contemporânea (COELHO, 2003).

Coelho (2003) enfatiza que o papel da Dialética social ou Teoria crítica do Direito é atingir não apenas a Teoria Geral do Direito, mas também todas as disciplinas inseridas numa perspectiva sociológica para que seja suprida a ausência do direito popular na lei do Estado. A teoria crítica tem suas bases epistemológicas em John Dewey e Paulo Freire, defensores da dialética da participação, uma forma de alcançar a libertação humana. 
Nesse sentido, entende-se que o Direito possibilita, de acordo com posicionamento de Freire (2016), um processo de libertação permanente, equidade social, na medida em que é uma construção na qual as classes oprimidas constroem sua libertação frente às classes opressoras, de tal forma que o direito compreende uma construção histórica que continua sendo um processo no qual são buscadas sempre novas expressões de justiça.

Com base nessas considerações, pode-se inferir que o Direito e sua função na sociedade vêm sendo analisados em várias perspectivas. Contudo, a que enfocamos é a da dimensão emancipatória do direito, oriunda da elaboração da teoria jurídica crítica.

A teoria crítica do Direito efetiva-se na construção de um Direito capaz de proporcionar condições de atendimento às demandas sociais e à efetivação das garantias constitucionais.

Para Clève (2001), a teoria crítica não pode limitar-se a criticar o Direito instituído no ordenamento legal, mas buscar construir uma teoria jurídica crítica que resgate a dimensão política do direito, a fim de concretizar as demandas sociais, as garantias constitucionais e a dignidade da pessoa humana, conforme disciplina a Constituição Federal.

As influências desse paradigma epistemológico no currículo são significativas e mudam radicalmente a forma de pensar e processar o saber jurídico em sala de aula. $\mathrm{O}$ primeiro ponto a se destacar é que não verá o saber jurídico como corpo curricular constituído de saberes não interessados e desprovidos de caráter ideológico, mas reconhece que estes reproduzem os valores dominantes ao manter o engessamento da norma jurídica e sua hierarquia como posição de neutralidade e cientificismo.

Busca-se uma postura didática docente que se comprometa em desvelar as estruturas dominantes e questionar os arranjos que formatam a estrutura social dominante do saber jurídico. Para seu desvelamento, cumpre historicizar-se o saber jurídico cristalizado no currículo, dar uma nova dinâmica a partir das múltiplas determinações da prática social (BRANCO, 2014). São as práticas sociais que determinarão a modelação e a formatação do saber jurídico. Daí a importância de se estudar o saber jurídico a partir da práxis social.

O currículo dos cursos de graduação em Direito precisa ser analisado na produção de uma formação profissional crítica e reflexiva, no qual a estrutura dos cursos se organize a partir dele. A lente analítica só será possível quando aquele, que traduz o currículo e o saber jurídico corporificado em sala de aula, o faça a partir da crítica ao sistema capitalista que produz formas de dominação e de desigualdade. Contrapomo-nos ao caráter alienador do saber jurídico na direção de 
se buscar formas alternativas de aplicação da norma jurídica coerentes com o princípio da justiça social.

A Resolução CNE/CES nº 09/2004, ao instituir as Diretrizes Curriculares Nacionais aos cursos de Direito, dispõe, no art. $5^{\circ}$, sobre conteúdos e atividades pertinentes a três eixos de formação: fundamental, profissional e prática.

Para cumprir plenamente a formação de um profissional, esses eixos articulam-se com as habilidades e competências básicas, as quais não se cingem ao conhecimento e práticas das técnicas dogmáticas, mas abrangem um contexto plural, holístico do ser do Direito, que é construído de forma integrada e coerente com as necessidades do sistema educativo, com o desenvolvimento de competências e habilidades, conforme determina o art. $4^{\circ}$ da Resolução CNE/CES nº 09/2004, in verbis:

Art. $4^{\circ}$. O curso de graduação em Direito deverá possibilitar a formação profissional que revele, pelo menos, as seguintes habilidades e competências: I - Leitura, compreensão e elaboração de textos, atos e documentos jurídicos normativos, com a devida utilização das normas técnico-jurídicas; II - Interpretação e aplicação do Direito, III - Pesquisa e utilização da legislação, jurisprudência, da doutrina e de outras fontes do Direito; IV Adequada atuação técnico-jurídica, em diferentes instâncias, administrativas ou judiciais, com a devida utilização de processos, atos e procedimentos; V - Correta utilização da terminologia jurídica ou da ciência do Direito; VI - Utilização de raciocínio jurídico, de argumentação, de persuasão e de reflexão crítica; VII - Julgamento e tomada de decisões; VIII - Domínio de tecnologias e métodos para permanente compreensão e aplicação do Direito (BRASIL, 2004).

Cumpre reconhecer que, diante dessas competências e habilidades, são colocados desafios à universidade quanto à formação de um profissional em construção permanente.

Nesse panorama, situam-se novos desafios e perspectivas do ensino superior dos cursos de Direito. Identificam-se às práticas educativas novas metodologias ativas à Educação, as quais assumem a construção do conhecimento como traço definidor da apropriação da informação e confronto com a realidade, ou seja, com ênfase para as metodologias problematizadoras. Estas surgem como alternativas ao ensino tradicional, que parecem não trazer uma explicação, discussão mais aprofundada da realidade, ao menos como único método de ensino, diante das exigências do mundo moderno.

As metodologias ativas buscam caminhos para o desenvolvimento da autonomia profissional, a autodeterminação do aluno, pessoal e social. Portanto, indispensáveis para o desenvolvimento da consciência crítica, com o propósito de refletir sobre a realidade. Assim, a motivação do aluno passa a ser o ponto central de todo o processo de ensino-aprendizagem. $\mathrm{O}$ 
docente, nesse contexto, revela-se um parceiro, um motivador e um catalisador desse processo (AMARAL, 2014).

Essa concepção metodológica tem suas bases em um princípio teórico significativo: a autonomia, premissa de desenvolvimento humano explicitada nos estudos de Paulo Freire. Ainda com Freire, propõe-se a Educação numa perspectiva libertadora, salientando-se que o professor ponha em prática sua capacidade de autogerenciar ou autogovernar seu processo de formação.

As metodologias ativas de ensino integram-se em processos de conhecimento, análise, estudos, pesquisas e decisões individuais ou coletivas, com a finalidade de encontrar soluções para um problema. Nessa realidade metodológica, o docente atua como facilitador ou orientador para que o estudante faça pesquisas, reflita e decida por ele mesmo o que fazer para atingir os objetivos estabelecidos (BERBEL, 2011).

Com fundamento nas reflexões e na teia de saberes situados nessa linha de atuação didático-metodológica, compreendemos que as metodologias ativas baseiam-se em formas de desenvolver o processo de aprender, utilizando experiências reais ou simuladas, visando às condições de solucionar desafios oriundos das atividades essenciais da prática social, em diferentes contextos.

Para fins didáticos em sala de aula, as metodologias ativas aproveitam a problematização como estratégia de ensino/aprendizagem, com o objetivo de alcançar e motivar o aluno, pois, diante do problema, ele se detém, examina, reflete, relaciona a sua história e passa a ressignificar suas descobertas.

\section{CONCLUSÃO}

Não se pode negar que o positivismo jurídico ainda exerce forte influência no meio jurídico, seja na Universidade, seja nas Instituições do Poder Judiciário. Observa-se, na realidade social cotidiana, que o Direito posto em prática muitas vezes não é o Direito proposto pelos órgãos responsáveis por sua elaboração e execução. Percebe-se um descompasso entre os anseios da sociedade, o que a legislação determina e a efetivação prática do Direito.

Os apontamentos deste artigo nos permitem compreender que o ensino jurídico perpassa por normas legais, postulados, dogmas e técnicas jurídicas. Além disso, ultrapassa a retórica e o utilitarismo, sendo imprescindível reconhecer que o Brasil é um país complexo, repleto de conflitos, desafios e carências que precisam ser postos no debate jurídico, social e democrático, em um verdadeiro exercício de problematizar a realidade. 
Nessa ótica, o ensino do Direito deve assegurar a formação profissional e cidadã mais ampla, inter e multidisciplinar, com a perspectiva de implementar novas práticas no âmbito de atuação profissional de forma crítica e responsável diante dos conflitos humanos e sociais.

Para tanto, as Diretrizes Curriculares Nacionais para o curso de Direito apresentam competências e habilidades ao profissional inerentes à argumentação, à criticidade e à busca por soluções jurídicas para seus clientes, de modo a provocar mudanças na formação dos profissionais do Direito, com consequentes reflexos individuais e sociais no tratamento das demandas jurídicas.

\section{REFERÊNCIAS}

AMARAL, Larissa M. do. Entre cativar e qualificar: os desafios do professor de direito por uma abordagem dos métodos de ensino participativo. In: CONGRESSO NACIONAL CONPEDIDIREITO, EDUCAÇÃO E METODOLOGIAS JURÍDICOS, 12., 2014. [S.1.]. Anais... [S.1.: s.n.], 2014. Disponível em: <http://www.publicadireito.com.br/artigos/?cod=670f0c94cc5271fe>. Acesso em: 15 maio 2016.

BERBEL, N.A. N. As metodologias ativas e a promoção da autonomia de estudantes. Seminário: Ciências Sociais e Humanas, Londrina, v. 32, n. 1, p. 25-40, jan./jun. 2011.

BRASIL. Conselho Nacional de Educação. Câmara de Educação Superior. Resolução CNE/CES $\mathbf{n}^{\circ}$ 9, de 29 de setembro de 2004. Institui as Diretrizes Curriculares Nacionais do Curso de Graduação em Direito e dá outras providências. Brasília, DF, 2004. Disponível em: <http://portal.mec.gov.br/cne/arquivos/pdf/rces09_04.pdf>. Acesso em: 18 abr. 2016.

BRANCO, José N. O. C. O ensino jurídico: algumas reflexões para novas perspectivas. Rev. eGaia Conhecimento Jurídico, ano 1, v. 1, n.1, Caxias, jul. 2014.

Constituição da República Federativa do Brasil de 1988. Brasília, DF, 1988. Disponível em: <http://www.planalto.gov.br/ccivil_03/Constituicao/Constituicao.htm>. Acesso em: 20 abr. 2016.

. Lei n 9.394, de 20 de dezembro de 1996. Estabelece as Diretrizes e Bases da Educação Nacional. Brasília, DF, 1996. Disponível em: <http://www.planalto.gov. br/ccivil_03/leis/L9394.htm>. Acesso em: 18 abr. 2016.

CLÈVE, Clèmerson Merlin. O Direito e os direitos: elementos para uma crítica do direito contemporâneo. 3. ed. Belo Horizonte: Fórum, 2011.

COELHO, Luiz Fernando. Teoria crítica do Direito. 2. ed. Belo Horizonte: Del Rey, 2003.

FEFERBAUM, Marina; GHIRARDI, José Garcez (orgs). Ensino do Direito para um mundo em transformação. São Paulo: FGV, 2012. 
FREIRE, Paulo. Pedagogia da autonomia: saberes necessários a prática educativa. 53. ed. São Paulo: Paz e Terra, 2016.

MARTINEZ, Sérgio Rodrigo. Manual da educação jurídica. Curitiba: Juruá, 2003.

MIKOS, Nádia R. C.; VILLATORE, Marco A. C. Dos paradigmas educacionais e sua aplicação ao ensino do Direito. Revista Brasileira de Educação e Cultura: Num. XIII, jan-jun 2016.

RODRIGUES, Horácio Wanderlei; ARRUDA, Edmundo Lima Júnior. (orgs). Educação jurídica (Coleção - Pensando o Direito no séc. XXI. Vol. II). 2. ed. Florianópolis: FUNJAB, 2012.

SANTOS, André Luís Lopes dos. Ensino jurídico: uma abordagem político educacional. Campinas: Edicamp, 2002.

WOLKMER, Antonio Carlos. História do Direito no Brasil. 9. ed. Rio de Janeiro: Forense, 2015a.

. Introdução ao pensamento jurídico crítico. 9. ed. São Paulo: Saraiva, $2015 b$. 